\title{
Undercatch of tipping-bucket gauges in high rain rate events
}

\author{
C. E. Duchon and C. J. Biddle \\ University of Oklahoma, Norman, Oklahoma, USA \\ Received: 15 October 2009 - Revised: 25 January 2010 - Accepted: 7 February 2010 - Published: 8 March 2010
}

\begin{abstract}
We have investigated differences in rainfall accumulations for seven high rain rate events from three gauges: a Geonor T-200B vibrating-wire weighing gauge and two MetOne tipping-bucket gauges. The Geonor gauge and one tipping-bucket gauge are located in a pit so that their collection orifices are at ground level. Thus their measured rainfall accumulations are minimally affected by wind speed. The other tipping-bucket gauge is located $105 \mathrm{~m}$ from the pit and is surrounded by an Alter-type slatted wind screen. Its collection orifice is positioned $1 \mathrm{~m}$ above ground level.

The results from the seven events show that the tippingbucket gauges noticeably underestimated storm event rainfall totals relative to the weighing-bucket gauge when 1-min rain rates exceeded about $50 \mathrm{~mm} / \mathrm{h}(2 \mathrm{in} / \mathrm{h})$. In addition, we conclude that observable wind induced undercatch by the aboveground tipping bucket gauge begins when the wind speed at a height of $2 \mathrm{~m}$ exceeds around $5 \mathrm{~m} / \mathrm{s}$. In this paper we show and discuss time series of rain rates, differences in rain rates, and wind speeds for two of the seven events in an attempt to account for the lower storm totals from the two tipping bucket gauges relative to the weighing-bucket gauge.
\end{abstract}

\section{Introduction}

It is well known that tipping-bucket gauges undercatch the actual amount of rain as the rain rate (or rain intensity) increases. The reason for undercatch, as explained by Duchon and Essenberg (2001), is that rain is not being measured during the finite time required for the bucket to tip from one side to the other. The motivation for our investigation is that, ultimately, we want to develop an algorithm for correcting tipping-bucket measurements of rainfall given the elapsed time between successive tips. Both laboratory and field observations will be used to determine the magnitude of undercatch.

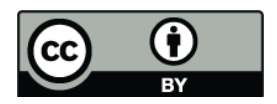

Correspondence to: C. E. Duchon (cduchon@ou.edu)
In this paper we show and discuss time series of rain rates and wind speed during two high rain rate events from among the seven we studied. With the weighing-bucket gauge in the pit used as the reference gauge, one tipping-bucket gauge also in the pit, and the other above ground, in principle, we can use the three gauges to estimate undercatch of the tipping-bucket gauges due to both high rain rates and high wind speed. In the first case presented here, we had only two gauges: the weighing-bucket gauge in the pit and an aboveground tipping-bucket gauge. We present this case, though, because of the persistent high rain rates that resulted in substantial undercatch from the tipping-bucket gauge.

\section{Description of field site and data acquisition}

The data used in this study were acquired at a field site $\left(97.465^{\circ} \mathrm{W}, 35.236^{\circ} \mathrm{N}\right)$ located on the north campus of the University of Oklahoma, Norman that has good exposure in all directions. Figure 1 is a view looking northwest showing the pit in the foreground containing a MetOne tipping-bucket gauge, denoted TP, and a Geonor T-200B weighing-bucket gauge, denoted WP. Their orifices are positioned about $1 \mathrm{~cm}$ above the fabric that covers the grill to prevent splashing of raindrops. A second tipping-bucket gauge, denoted TN and identical to that in the pit, is located at the Norman site of the Oklahoma Mesonet (Brock et al., 1995) seen in the background in Fig. 1. Figure 2 shows the interior of the pit with the tipping-bucket gauge in the foreground and the weighingbucket gauge in the background. The collector diameter of the former is $30.5 \mathrm{~cm}$ (12 in) and the latter $16 \mathrm{~cm}$ (6.3 in). The interior dimensions of the pit are $3.7 \mathrm{~m} \times 1.8 \mathrm{~m} \times 1.4 \mathrm{~m}$ deep.

The tipping-bucket gauge TN at the Norman Mesonet site including its Alter windshield (Alter, 1937) is shown in Fig. 3. The tipping-bucket gauges are periodically calibrated by Oklahoma Mesonet personnel and the calibration of the three-wire Geonor is validated annually (Duchon, 2008)

All data were collected on Campbell Scientific, Inc. data loggers. One-min accumulations from each gauge and onemin averages of wind speed and wind direction taken four

Published by Copernicus Publications on behalf of the European Geosciences Union. 


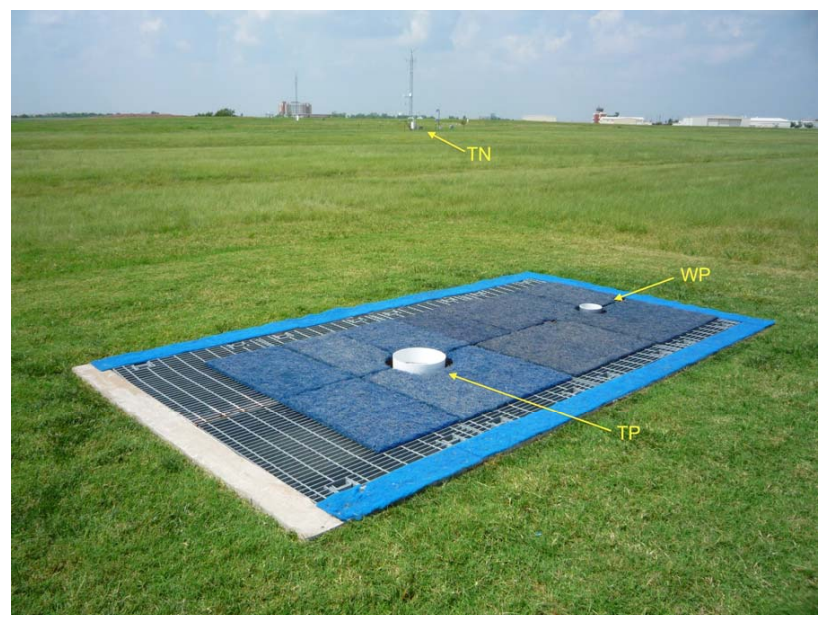

Fig. 1. View of field site looking northwest. In the foreground is the closed pit with tipping-bucket gauge TP and weighing-bucket gauge WP; in the background is tipping-bucket gauge TN (not easily discernible, but see Fig. 3) located at the Norman Mesonet site.

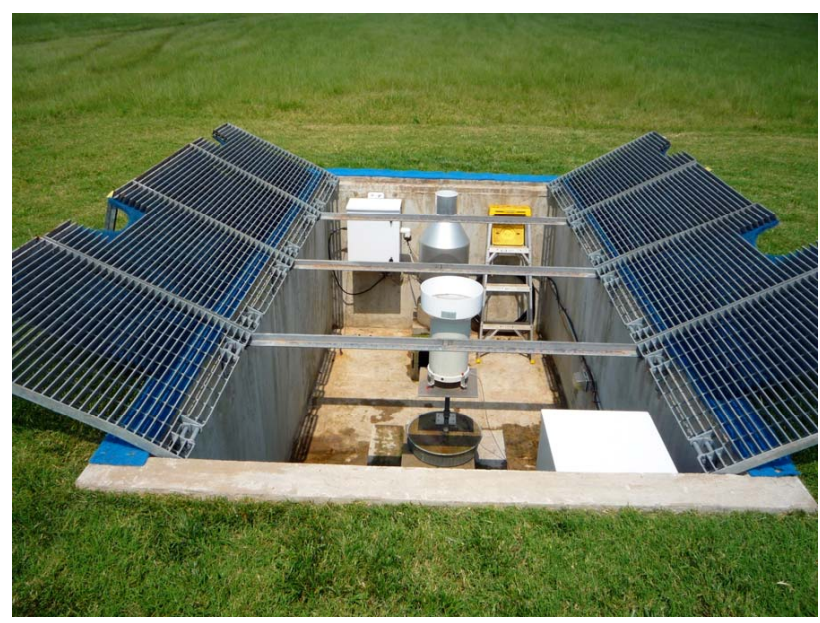

Fig. 2. View of the opened pit with the TP gauge (foreground) and WP gauge (background).

meters south of the pit at a height of two meters were transmitted and archived at the Oklahoma Climatological Survey at the University.

\section{High rain rate events}

\subsection{August 2007}

This high rain rate event was a consequence of Tropical Storm (TS) Erin that formed over the western tip of Cuba, weakened to a remnant low pressure area after making landfall along the Texas coast, and reintensified to TS strength as it progressed northeastward across Oklahoma (Galarneau

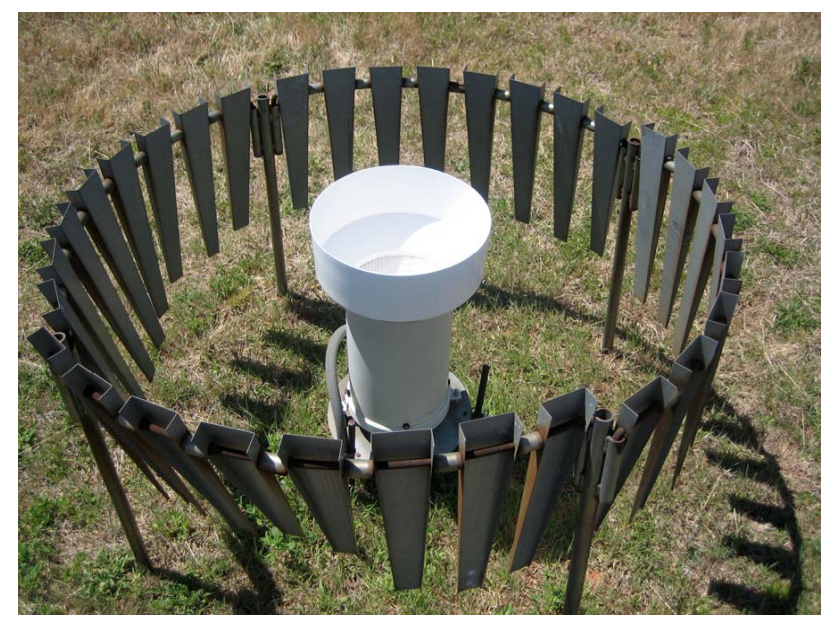

Fig. 3. Close-up of the TN gauge at the Norman Mesonet site with surrounding wind shield.

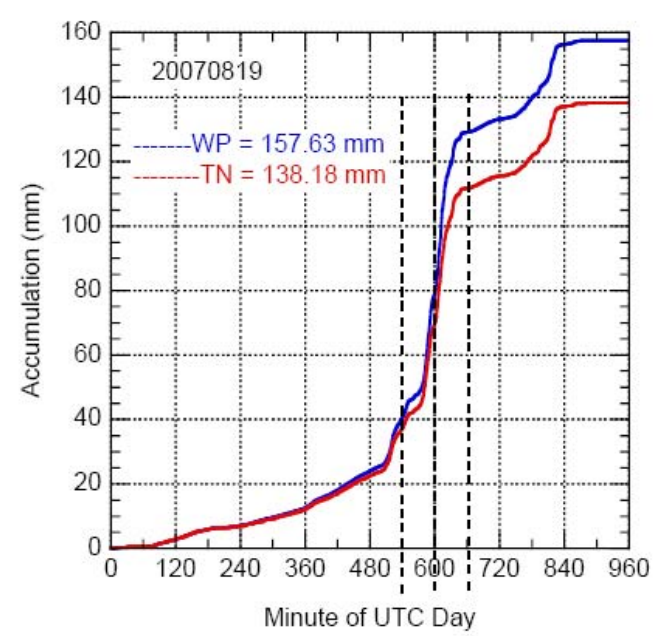

Fig. 4. One-min rain accumulations at Norman, OK, $19 \mathrm{Au}-$ gust 2007. WP is in the pit and TN is at the Norman Mesonet site. The dashed vertical lines define two successive 60 -min periods.

et al., 2009). This rare phenomenon produced very heavy rainfall in the central part of the state, an example of which is seen in Fig. 4 observed at the north campus field site. Because the tipping-bucket gauge in the pit, TP, was not installed until November 2007, comparable measurements are available only from the aboveground Norman Mesonet tipping-bucket gauge, TN, and the weighing-bucket gauge in the pit, WP.

Figure 4 shows two successive $60-$ min periods (min 540600 and 600-660) of high rain rate defined by the dashed vertical lines. At the end of the second period the difference in accumulation from the two gauges is $17.3 \mathrm{~mm}$. In order to account for the accumulated difference, we first examine the rain rates during these two periods. 


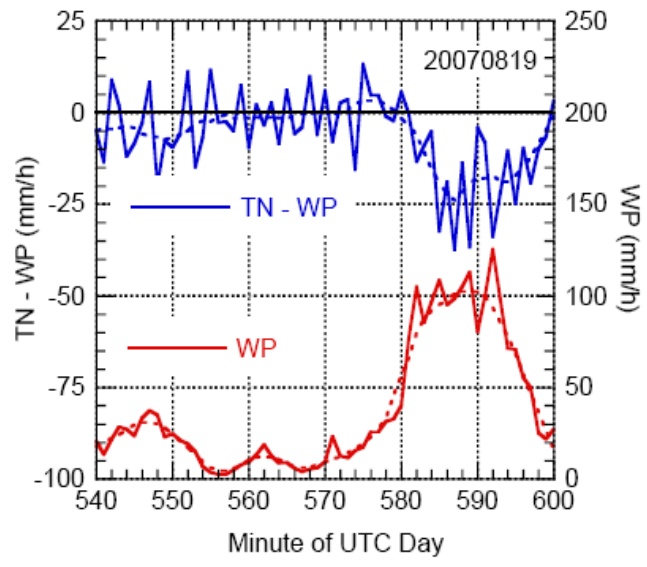

Fig. 5. One-min rain rate differences $\mathrm{TN}-\mathrm{WP}$ and rain rate from WP for the first 60-min period in Fig. 4. Solid lines are one-min observed values and dashed lines are smooth fits.

Figure 5 shows the difference in rain rates between the two gauges (blue lines, left-hand axis) for the first period along with rain rate from WP (red lines, right-hand axis), the reference gauge. The dashed lines are smooth fits to their respective solid lines using a locally weighted least squares smoothing scheme developed by Cleveland (1979) and called LOWESS or LOESS. We chose a value of 0.15 for the smoothing parameter associated with the scheme. The only purpose of the smoothing is to enhance visual perception of the plot. All rain rates are in units of $\mathrm{mm} / \mathrm{h}$ and are calculated by subtracting two successive one-min accumulations and multiplying the difference by 60 .

Whereas the rain rates from WP are derived from actual accumulation in the bucket at the end of each min, the rain rates from TN (and later TP) are derived from accumulated amounts in increments of $0.254 \mathrm{~mm}$ (0.01 in). This results in recorded rain rates in increments of $15.24 \mathrm{~mm} / \mathrm{h}$. The reported accumulation at the end of a given min is correct only to the last tip of the bucket (apart from any consideration of undercatch). The missing amount is taken into account at the end of the min that includes the next tip of the bucket. The effect of this discretization is the seesaw pattern of rain rate differences, TN-WP, seen in Fig. 5. Thus there is some incompatibility when comparing rain rates from a tippingbucket gauge and a weighing-bucket gauge. It is necessary, therefore, to mentally or mathematically (as in Fig. 5) smooth variables involving one-min rain rates from a tipping-bucket gauge.

Figure 5 clearly shows that as the rain rate from WP exceeds around $50 \mathrm{~mm} / \mathrm{h}$ there is a significant decrease in the rain rate from $\mathrm{TN}$ relative to that from $\mathrm{WP}$, reaching a maximum of about $25 \mathrm{~mm} / \mathrm{h}$ around $\min 590$. There is also modest undercatch from TN from min 540 to about min 557 (but which may be wind induced).

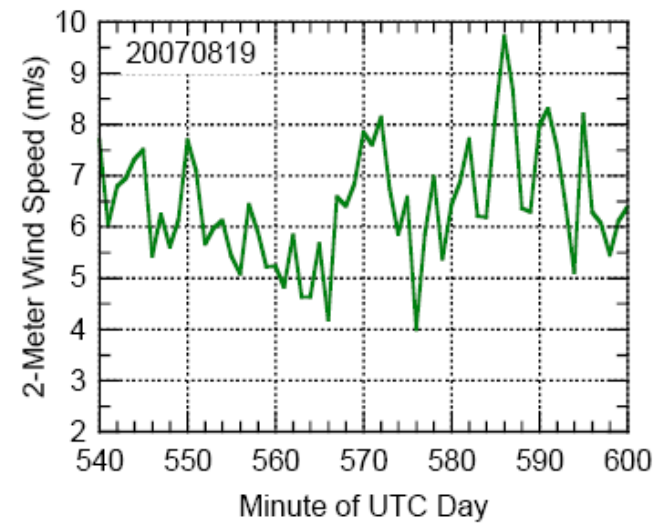

Fig. 6. One-min average wind speeds at 2-m height during first 60-min period.

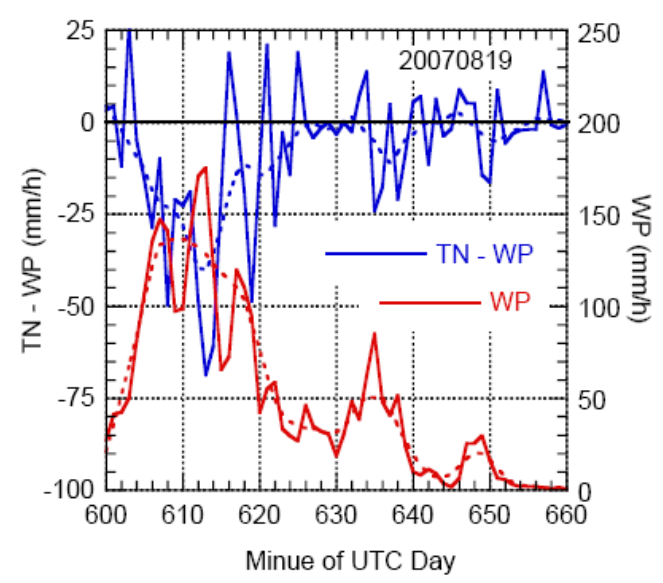

Fig. 7. Same as Fig. 5 but for second 60-min period.

The contemporaneous 2-m wind speed measured south of the pit is shown in Fig. 6. It is noteworthy that wind speeds above $6 \mathrm{~m} / \mathrm{s}$ occur during both the period of modest undercatch 540-557 and the period of substantial undercatch 580600 . The purpose of surrounding the TN gauge with an Alter wind shield is to reduce the undercatch. However, Duchon and Essenberg (2001) conclude that the effect of the Alter shield in reducing wind-induced undercatch (or increasing measured rainfall) is usually less than $1 \%$ based on approximately 100 rain events. Our analysis of the second rain event in this paper and the other five events indicates that noticeable undercatch can begin at a wind speed around $5 \mathrm{~m} / \mathrm{s}$. Based on this analysis, we conclude that the undercatch for period 580-600 is due to both wind speed and rain loss associated with the time increment required for the bucket to tip.

Rain rate results for the second 60-min period are shown in Fig. 7. Observed WP rain rates continuously exceed $50 \mathrm{~mm} / \mathrm{h}$ from $603-622$ reaching a maximum of approximately $175 \mathrm{~mm} / \mathrm{h}$, considerably higher than occurred in the 


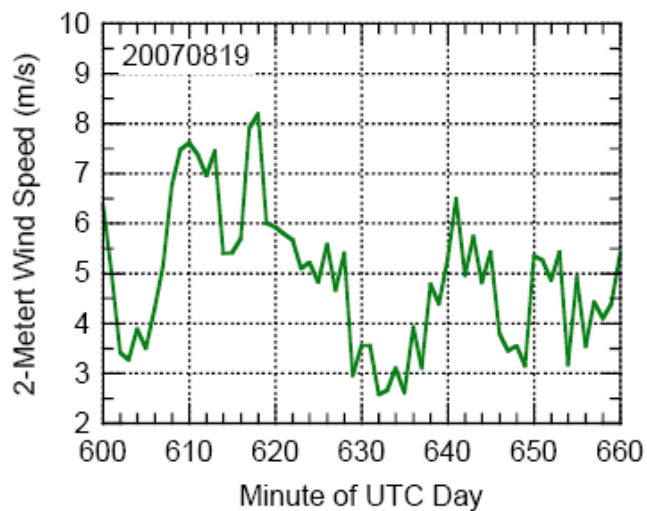

Fig. 8. Same as Fig. 6 but for second $60-$ min period.

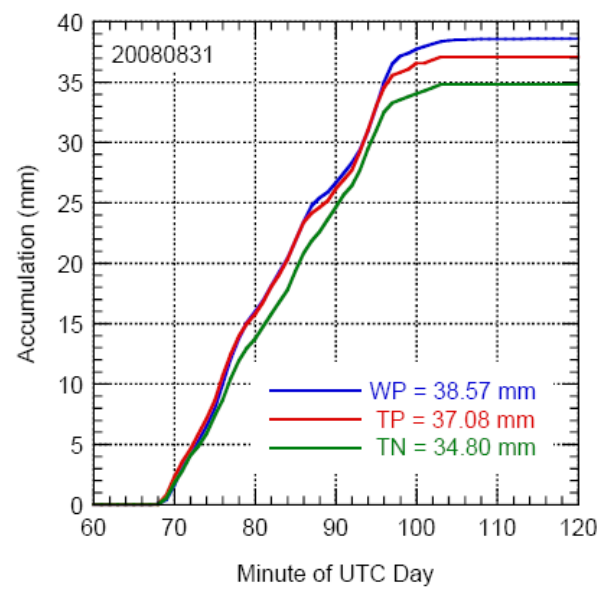

Fig. 9. One-min rain accumulations at Norman, OK, $31 \mathrm{Au}-$ gust 2008 for the three gauges.

first 60-min period. As expected, the undercatch also increases. The smooth dashed curves can be used to some advantage to see the relation between undercatch rain rate $\mathrm{TN}-\mathrm{WP}$ and rain rate WP.

Again, as seen in Fig. 8, wind speeds greater than $6 \mathrm{~m} / \mathrm{s}$ occur within the period of substantial undercatch and high rain rate, min 608-619. Similar to Fig. 5, we expect both wind speed and high rain rate contribute to the undercatch in Fig. 7.

\subsection{August 2008}

Figure 9 shows rain accumulation from min 60-120 on 31 August 2008 from three gauges, the tipping bucket and weighing bucket in the pit, and the tipping bucket at the Norman Mesonet site. All the rain on this day occurred during this 60 -min period. The gauges in the pit should be minimally affected by wind so we would expect (1) the difference in accumulation between the two gauges in the pit to reflect undercatch by TP (relative to the weighing bucket WP) due to

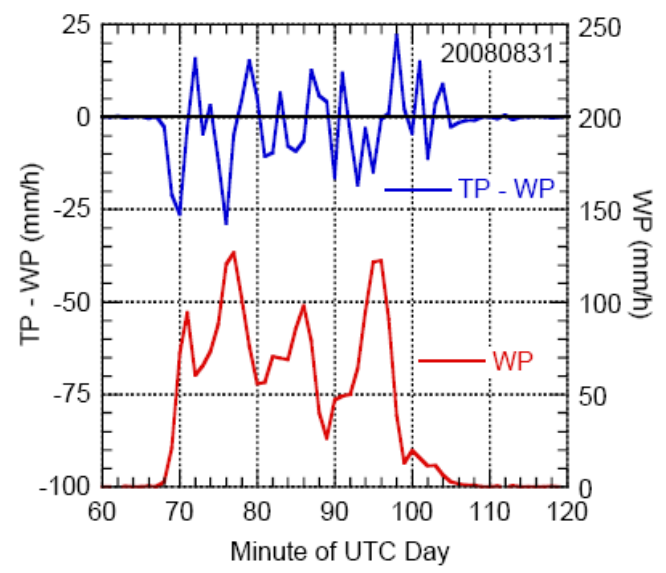

Fig. 10. One-min rain rate differences TP-WP and rain rate from WP for the event in Fig. 9.

high rain rate and (2) the difference between the two tippingbucket gauges TN and TP to indicate the effect of wind speed on undercatch. We expect further that natural variabilities in rainfall and wind speed due to the separation between $\mathrm{TN}$ and TP $(105 \mathrm{~m})$ are minor and should not alter our conclusions. In fact, the 1-min average 2-m wind speeds at both locations are substantially alike. From Fig. 9 and with regard to (1), the accumulated difference is $1.49 \mathrm{~mm}$ ( $4 \%$ undercatch); for (2), the accumulated difference is $2.28 \mathrm{~mm}$, indicating the wind effect for this event is about 1.5 times the undercatch due to high rain rate.

Rain rates from WP along with rain rate differences from TP-WP are shown in Fig. 10. Smooth curves are not shown because they didn't improve the visual perception of the plot (which applies, also, to Figs. 11 and 12). We can see that the valleys in rain rate differences appear to be generally associated with peaks in rain rate around $100 \mathrm{~mm} / \mathrm{h}$ for WP. If we sum the rain rate differences, divide by $60 \mathrm{~min} / \mathrm{h}$, and again divide by $0.254 \mathrm{~mm} / \mathrm{tip}$, we find there are 6 tips too few to match the $60-\mathrm{min}$ total of $38.57 \mathrm{~mm}$ from WP. A similar relationship follows between TN-WP and WP as seen in Fig. 11. Here there is a difference of 15 tips.

With respect to (2) above, Fig. 12 shows rain rate differences TN-TP and their relation to 1-min wind speeds. The general conclusion is that higher wind speeds, say, greater than about $5 \mathrm{~m} / \mathrm{s}$, tend to be associated with systematic undercatch by TN relative to TP. We observe that the values of $\mathrm{TN}-\mathrm{TP}$ are in increments of $15.24 \mathrm{~mm} / \mathrm{h}$, which corresponds to one tip of the bucket in one min. There is an undercatch of 9 tips of $\mathrm{TN}$ relative to $\mathrm{TB}$, thereby yielding a difference in accumulation of $2.28 \mathrm{~mm}$.

Correcting observed rainfall for undercatch due to wind speed is quite problematic. Apart from dealing with discretization of measured rain when using a tipping-bucket gauge, the influence of the distribution of drop sizes on undercatch must be considered. Various laboratory and numerical simulation studies, e.g., Folland (1988) and Nešpor 


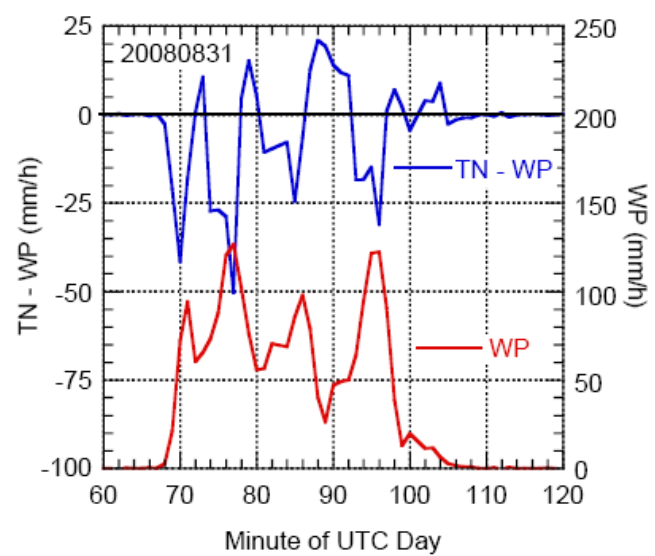

Fig. 11. One-min rain rate differences $T N-W P$ and rain rate from WP for the event in Fig. 9.

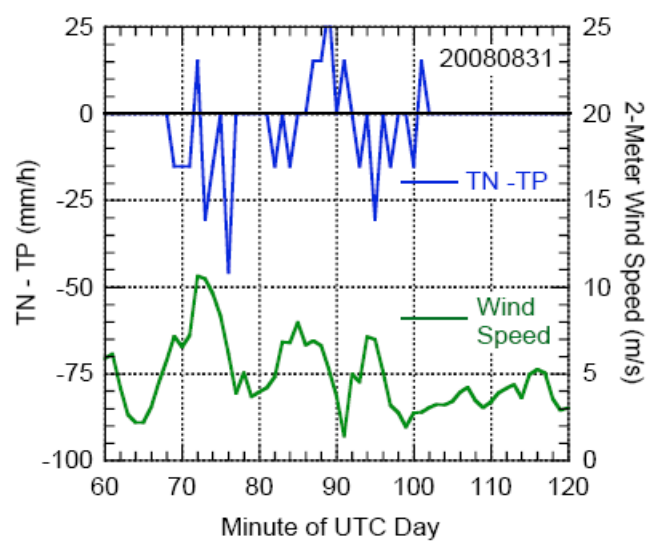

Fig. 12. One-min rain rate differences TN-TP and 2-m wind speed for the event in Fig. 9.

and Sevruk (1999) have shown the existence of relationships among rain rate, wind speed, and drop-size distribution in accounting for undercatch by a given gauge. Drop-size distribution measurements, unfortunately, are relatively rare and none were made as part of this study.

\section{Conclusions from these and other high rain rate events}

In this paper we showed and discussed systematic effects of undercatch due to high rain rate and wind speed for two events that produced heavy to extremely heavy rainfall. Not discussed here are the investigations of five other high rain rate events that ranged from moderate to heavy total accumulation.

Based on these seven events, we conclude that: (1) the effect of rain rate on undercatch from tipping bucket gauges of the type used here becomes clearly significant only when the rain rate exceeds about $50 \mathrm{~mm} / \mathrm{h}(2 \mathrm{in} / \mathrm{h}) ;(2)$ the effect of wind speed on undercatch becomes clearly significant only when its magnitude exceeds about $5-6 \mathrm{~m} / \mathrm{s}$ at a height of $2 \mathrm{~m}$; and (3) when high wind speed and high rain rates occur together, the arrangement of the three gauges described here offers the possibility of separating the undercatch from each source. To do so with confidence requires measuring the time of tip of the buckets, a procedure currently under evaluation.

Acknowledgements. We express our thanks to personnel of the Oklahoma Climatological Survey, especially Chris Fiebrich, David Grimsley, Ryan Brashear, and David Demco, for their steadfast support of this work.

Edited by: S. C. Michaelides

Reviewed by: W. B. Crosson and R. Hale

\section{References}

Alter, C. J.: Shielded storage precipitation gages, Mon. Weather Rev., 65, 262-265, 1937.

Brock, F. V., Crawford, K. C., Elliot, R. L., Cuperus, G. W., Stadler, S. J., Johnson, H. L., and Eilts, M. D.: The Oklahoma Mesonet: A technical review, J. Atmos. Oceanic Technol., 12, 5-19, 1995.

Cleveland, W. S.: Robust locally weighted regression and smoothing scatterplots, J. Am. Stat. Assoc., 74, 829-836, 1979.

Duchon, C. E. and Essenberg, G. R.: Comparative rainfall observations from pit and aboveground gauges with and without wind shields, Water Resour. Res., 37(12), 3253-3263, 2001.

Duchon, C. E.: Using vibrating-wire technology for precipitation measurements, Chapter 2, in: Precipitation: Advances in Measurement, Estimation and Prediction, edited by: Michaelides, S., Springer, ISBN: 978-3-540-77654-3, 2008.

Folland, C. K.: Numerical models of the raingauge exposure problem, field experiments and an improved collector design, Q. J. R. Meteorol. Soc., 114, 1485-1516, 1988.

Galarneau, Jr., T. J., Bosart, L. F., and Schumacher, R. S.: Reintensification of Tropical Storm Erin (2007) over Oklahoma, Bull. Amer. Meteor. Soc., 90(3), 306-308, 2009.

Nešpor, V. and Sevruk, B.: Estimation of wind-induced error of rainfall gauge measurements using a numerical simulation, J. Atmos. Oceanic Technol., 16, 450-464, 1999. 